\title{
Microstructural and mechanical characteristics of W-2Ti and W-1TiC processed by hot isostatic pressing
}

\author{
A. Muñoz ，B. Savoini , E. Tejado , M.A. Monge , J.Y. Pastor , R. Pareja
}

\begin{abstract}
A B S T R A C T
W-2Ti and W-1TiC alloys were produced by mechanical alloying and consolidation by hot isostatic pressing. The composition and microstructural characteristics of these alloys were studied by X-ray diffraction, energy dispersion spectroscopy and scanning electron microscopy. The mechanical behavior of the consolidated alloys was characterized by microhardness measurements and three point bending tests. The mechanical characteristics of the $\mathrm{W}-2 \mathrm{Ti}$ alloy appear to be related to solution hardening. In $\mathrm{W}-1 \mathrm{TiC}$, the residual porosity should be responsible for the poor behavior observed in comparison with W-2Ti.
\end{abstract}

\section{Introduction}

In the last years a great number of research works related to the development and characterization of $\mathrm{W}$-based materials have been carried out $[1-3 \mid$. It is due to the fact that $W$ and $W$ alloys are candidate materials to be used in the future fusion devices, in particular for the divertor and other first wall components [4-G]. W accomplishes some of the requirements for the plasma facing components of the fusion reactors, such as high melting point, good thermal conductivity, resistance to high thermal shocks. minimal tritium retention and low sputtering erosion rates. However, $W$ has some critical issues that will have to be overcame or reduced for being used in fusion devices. In particular, it is brittle with a ductile-brittle transition temperature around $400^{\circ} \mathrm{C}$ and a recrystallization temperature between 1200 and $1300^{\circ} \mathrm{C}$. l'wo possible strategies are considered for increasing $W$ ductility: alloying and nanostructuring [7-9]. Concerning alloying, $W$-Re alloys are more ductile than pure $W$, however they have been rejected for fusion applications because they suffer irradiation embrittlement due to Re impurity transmutation into deleterious impurities, besides being very expensive $[10,11]$. Moreover, other property required to the first wall materials is to be classified as a low or reduced activation material, thus only $\mathrm{Fe}, \mathrm{Cr}, \mathrm{V}, \mathrm{Ti}, \mathrm{Si}$ and $\mathrm{C}$ should be considered as potential alloying elements. On the other hand, materials with an ultrafine-grained (UFG) microstructure usually exhibit enhanced ductility. In addition, it would be expected that a UFG microstructure improves the irradiation resistance of $W$, as grain boundaries can be strong sinks for the irradiation induced defects. In relation to the recrystallization temperature. a fine dispersion of hard particles such as $\mathrm{La}_{2} \mathrm{O}_{3}, \mathrm{Y}_{2} \mathrm{O}_{3}$ or TiC may have capability for inhibiting grain growth and increases the recrystallization temperature, $W$ materials are usually fabricated by powder metallurgy routes due to its high melting point. In the case of processing $W$ alloys, the mechanical milling is a critical step for alloying and attaining both grain refinement and homogeneous solution or dispersion of nanosized particles, i.e. for developing a nanostructured material [12]. For achieving a consolidated $W$ material with a suitable density and mechanical properties, very high sintering temperatures under reducing conditions are required. Hot isostatic pressing (HIP) is a consolidation technique that is very successful for producing $W$ alloys, in particular untextured UFG oxide dispersion strengthened (ODS) W-Ti and $\mathrm{W}-\mathrm{V}$ alloys containing a nanosized dispersion of oxide particles $[13,14]$. Furthermore, these research works have shown that both $\mathrm{Ti}$ and $\mathrm{V}$ are sintering activators for the $W$ alloys, as their addition increases the densification degree. According to the $\mathrm{W}-\mathrm{V}$ and $\mathrm{W}$-li phase diagrams, the solubility in $\mathrm{W}$ is total for any $\mathrm{V}$ content and for a weight percent of $\mathrm{Ti}$ below $10 \%$. For small contents of these impurities the melting temperature of the alloy would maintain quite close to that for pure $W$. Recently, it has been showed that Ti addition might alter the core structure of the screw dislocations and their slip mechanism increasing $W$ ductility such as it occurs for Re impurities [15]. The present communication reports the development of $\mathrm{W}-2 \% \mathrm{li}$ and $\mathrm{W}-1 \% \mathrm{TiC}$ (wt.\%) materials processed by mechanical alloying and HIP. For $\mathrm{W}-2 \mathrm{Ti}$, the goal of the mechanical milling process will 
be to achieve the proper Ti alloying in $W$, and to analyze its effect on the mechanical behavior of the alloy. For $W-1 T i C$ the purpose is to achieve a good dispersion of the TiC nanoparticles in the $W$ matrix. The characterization of the materials during the different steps of the processing has been carried out to establish the optimum parameters in the fabrication process. The microstructure of the consolidated materials has also been studied, and the particular mechanical properties explored.

\section{Experimental procedure}

The alloys were prepared from $W$ and Ti elemental powders with purity of $99.9 \%$, and $99 \%$ and pure nano-sized TiC powder (Skyspring Nanomaterials). The particle sizes of the elemental powders were in the range $1-5 \mu \mathrm{m}$ for $W$, and 150 mesh $(<100 \mu \mathrm{m})$ for Ti. The average particle size for TiC was $\sim 40 \mathrm{~nm}$. The processing of the materials consisted of: (1) blending of the starting powders in a Turbular T2F mixer for $4 \mathrm{~h}$; (2) mechanical alloying of the blends at $150 \mathrm{rpm}$ in a high-energy planetary ball mill: (3) alloyed powder encapsulation and degassing: and (4) consolidation by HIP for $2 \mathrm{~h}$ at $1573 \mathrm{~K}$ and $195 \mathrm{MPa}$. The mechanical alloying was carried out under a high purity $\mathrm{Ar}$ atmosphere in a WC lined pot, using WC balls of $10 \mathrm{~mm}$ in diameter as grinding media at a ball-to-powder ratio of $4: 3$. The milling time was $75 \mathrm{~h}$ for $\mathrm{W}-2 \mathrm{Ti}$ and $50 \mathrm{~h}$ for $\mathrm{W}-1 \mathrm{TiC}$. Before the consolidation, the alloyed powder encapsulated in a steel container was degassed for $24 \mathrm{~h}$ at $400^{\circ} \mathrm{C}$ in a vacuum of $\sim 2 \times 10^{-3}$ mbar. This degassing process removes part of the volatile components that could have been incorporated to the powder during the milling process and handling.

The $\mathrm{O}$ content in the powders and consolidated materials was determined using a LECO TC500 analyzer. The initial O content of the elemental $\mathrm{W}, \mathrm{Ti}$ and $\mathrm{TiC}$ powders was $0.037 \%, 0.069 \%$ and $4.5 \%$, respectively, after handling in the glove box in Ar atmosphere. The clensity measurements of the consolidated alloys carried out in a He ultrapycnometer resulted in $\sim 98 \%$ for $W-2 \mathrm{Ti}$ and $\sim 95 \%$ for $W-$ $1 \mathrm{TiC}$ of the expected densities calculated applying the mixture rule for the corresponding composition (Table 1). The evolution of the particle morphology and structure of the powder during the milling process, and the microstructure of the consolidated alloys were investigated by scanning electron microscopy (SEM) and X-ray diffraction (XRD). For compositional and microstructural analyses of the milled powder by SEM and energy dispersive spectroscopy (EDS), powder samples were embedded into a conductive epoxy resin and the surface of the specimens suitably polished. The microstructure was also studied with an atomic force microscope (AFM) (XE-100, l'ark Systems). XRD patterns were analyzed by the Rietveld method using the Fullprof software [16]. To obtain correct measurements of the average crystallite size and crystal lattice strain produced by the milling process, the contribution of the diffractometer to the peak shape was determined from a precise XRD pattern from a reference sample. The instrumental and the microstructure effects on the peak broadening were extracted applying the integral breadth analysis assuming a pseudo-Voigt function for the peak shapes and isotropic broadening for strain and crystallite size [17].

The Vickers microhardness was measured applying a load of $2.94 \mathrm{~N}$ for $20 \mathrm{~s}$. The flexural strength of $2 \times 2 \times 25 \mathrm{~mm}^{3}$ samples

Table 1

Density, oxygen content and Vickers microhardness for consolidated W-2Ti and W-1TiC.

\begin{tabular}{llllll}
\hline & $\begin{array}{l}\rho_{\text {theis }} \\
\left(\mathrm{g} / \mathrm{cm}^{3}\right)\end{array}$ & $\begin{array}{l}\rho_{\text {expe }} \\
\left(\mathrm{g} / \mathrm{cm}^{3}\right)\end{array}$ & $\begin{array}{l}\rho_{\text {exp }} / \rho_{\text {rther }} \\
(\%)\end{array}$ & $\begin{array}{l}\text { O } \\
(\mathrm{wL. \%})\end{array}$ & \multicolumn{1}{l}{$\begin{array}{l}\mathrm{Hv} \\
(\mathrm{GPa})\end{array}$} \\
\hline W-2Ti & 18.059 & $17.708 \pm 5$ & 98.0 & 0.418 & $14.0 \pm 0.7$ \\
W-1TiC & 18.706 & $17.827 \pm 9$ & 95.3 & 0.454 & $7.0 \pm 0.4$ \\
\hline
\end{tabular}

in vacuum was determined from three-point bending tests carried out in a universal testing machine (Instron. Model 8800), at a crosshead speed of $0.1 \mathrm{~mm} / \mathrm{min}$, with the samples on a self-aligning stage having a span of $16 \mathrm{~mm}$. The stage with the sample was placed at the center of a high vacuum furnace mounted onto the testing machine, heated up to the test temperature using a heating rate of $5^{\circ} \mathrm{C} / \mathrm{min}$ and a dwell time of $15 \mathrm{~min}$. At least, two samples were tested for each temperature, Before testing, the samples were annealed for one hour at $1200^{\circ} \mathrm{C}$ in $\mathrm{H}_{2}$-rich atmosphere to relieve the possible residual stresses induced by the electro-discharge machining and preparation of the samples.

\section{Results and discussion}

\subsection{Milled powders}

Although the powder handling and milling were carried out under a high purity Ar atmosphere, oxygen contamination was obvious. Fig. 1 shows a continuous increase of the $O$ content with a similar increasing rate for both alloys, which indicates that the 0 intake is the same irrespective of the composition of the powder, at least for $50 \mathrm{~h}$ milling under the present conditions. Let us point out that the initial $\mathrm{O}$ content in the $\mathrm{W}$-1lic blends is remarkably higher than in $\mathrm{W}-2 \mathrm{Ti}$,

The milling effect on the XRD patterns is shown in Fig. 2. The broadening of the diffraction peaks is an obvious result of the grain refinement and plastic deformation in the powder particles. After milling for $5 \mathrm{~h}$ the XRD patterns exhibit diffraction peaks that correspond to a single bcc phase; peaks from hcp Ti or fcc TiC are not detected. The evolution of the average crystallite size and lattice strain with milling time is shown in Fig. 3. The cumulative grain refinement and lattice strain for $\mathrm{W}$-1TiC is apparently faster than for $W-2 T i$. From the linear increase of the lattice strain with milling time a strain rate of $1.00 \times 10^{4}$ and $1.33 \times 10^{4} \mathrm{~h}^{1}$ are respectively determined for $W-2 T i$ and $W-1 T i C$. At least milling for $25 \mathrm{~h}$ at the present conditions are required for getting grain refinement with average crystallite size of $\sim 20 \mathrm{~nm}$ in $W-1 T i C$, but in the case of $\mathrm{W}-2 \mathrm{Ti}, 50 \mathrm{~h}$ are necessary for attaining similar crystallite sizes. The addition of $1 \mathrm{wt} . \%$ of hard TiC particles in $\mathrm{W}-1 \mathrm{TiC}$, in contrast with 2 wt.\% of ductile Ti in W-2Ti, accounts for the observed evolution of crystallite size and lattice strain. During milling a significant part of the impact energy would be consumed to produce solid solution alloying, in the case of W-2Ti in addition to plastic deformation, particle fragmentation, grain refinement and cold welding of particles. However, in W-1TiC the impact energy consumption for interdiffusion or solid solution would not be significant if it is accepted that the TiC dispersion is directly accomplished by the mechanical effect of the milling, and

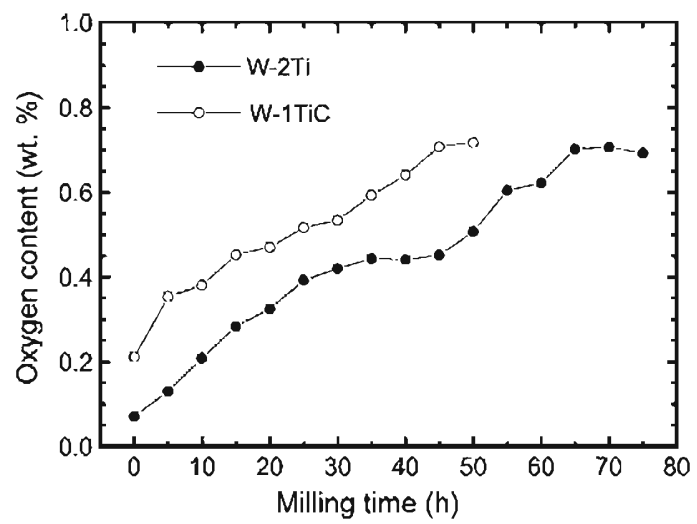

Fig: 1. Oxygen content versus milling time for $W-2 T i$ and $W-1$ Tic powders. 


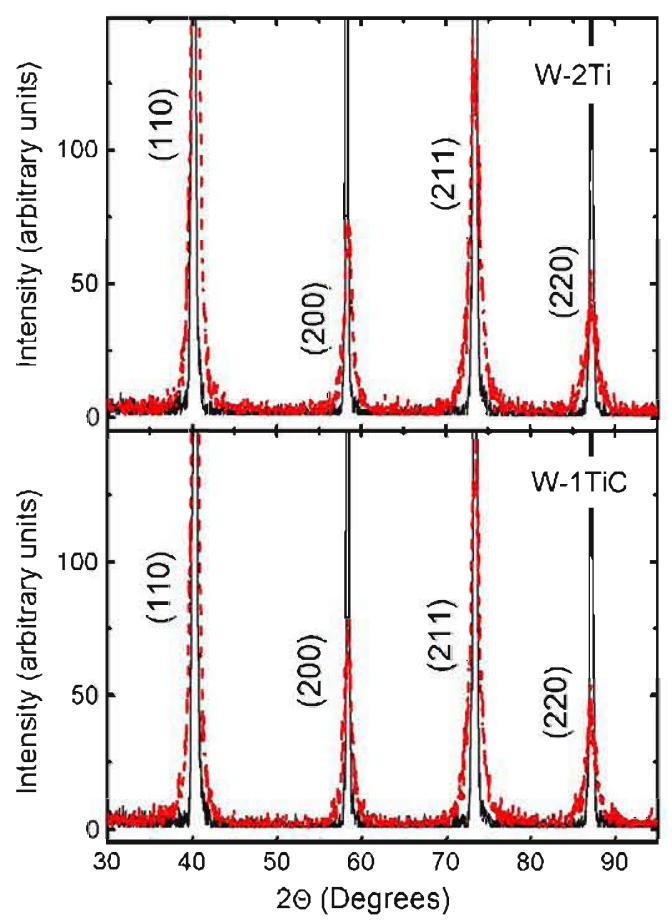

Fig. 2. XRD patterns for $\mathrm{W}-2 \mathrm{Ti}$ and $\mathrm{W}-1 \mathrm{TiC}$ powders: blended (solid) and after mechanical alloying (dashed) for 75 and $50 \mathrm{~h}$, respectively.

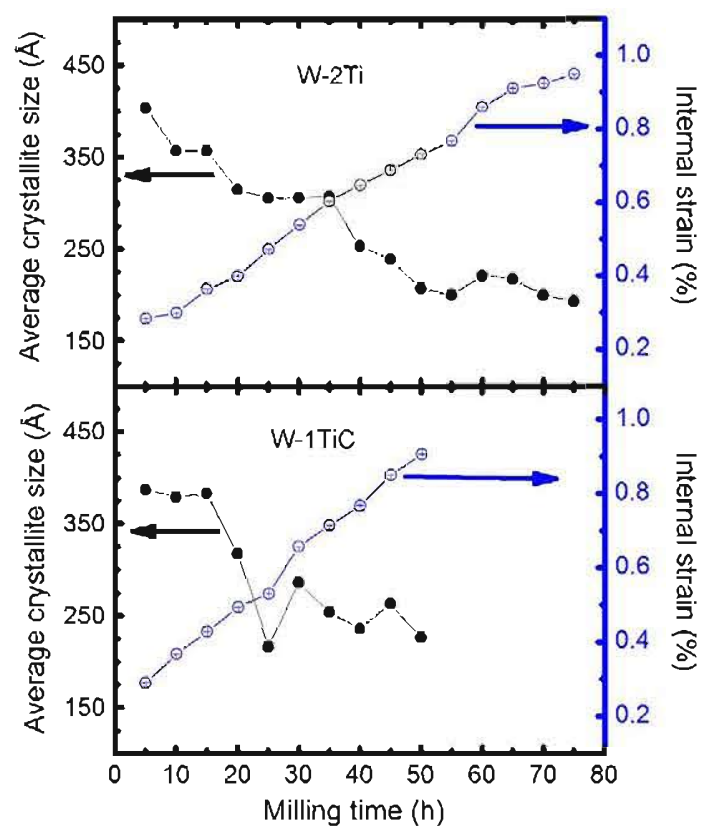

Fig. 3. Fffect of milling time nn the average crystallite size and internal sirain of the $W-2 T i$ and $W-1$ Tic powders.

not via TiC decomposition, i.e. Ti and $C$ dissolution in the $W$ lattice, and finally re-precipitation into nanosized TiC particles. Fig. 4 shows backscattered electron (BSE) images of the $\mathrm{W}-2 \mathrm{Ti}$ and $\mathrm{W}-$ 1 TiC powders after being mechanically alloyed for 75 and $50 \mathrm{~h}$, respectively. For $\mathrm{W}-2 \mathrm{Ti}$, the BSE image (Fig. $4 \mathrm{a}$ ) reveals the presence of sub-micron Ti-rich areas, indicated by arrows in the image. EDS analyses performed on the tungsten matrix indicate a Ti fraction slightly below the nominal one, indicating that a nearly complete solid solution is attained after milling for $75 \mathrm{~h}$ under the present conditions. In $\mathrm{W}-1 \mathrm{TiC}$ milled for $50 \mathrm{~h}$ (Fig. 4b), the
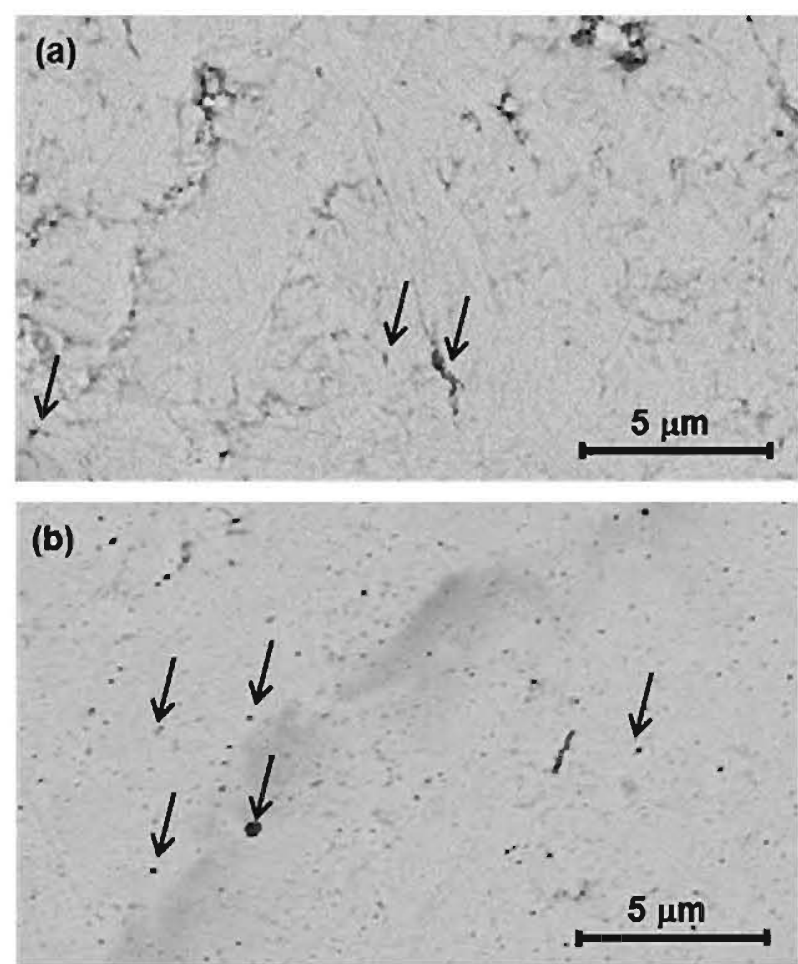

Fig. 4. EBS-SEM images of powder particles. (a) $\mathrm{W}-2 \mathrm{Ti}$ milled for $75 \mathrm{~h}$; the arrows point to sub-micrometer Ti-rich regions. (b) $\mathrm{W}-1 \mathrm{TiC}$ milled for $50 \mathrm{~h}$; the arrows indicate sub-micrometer TiC particles.
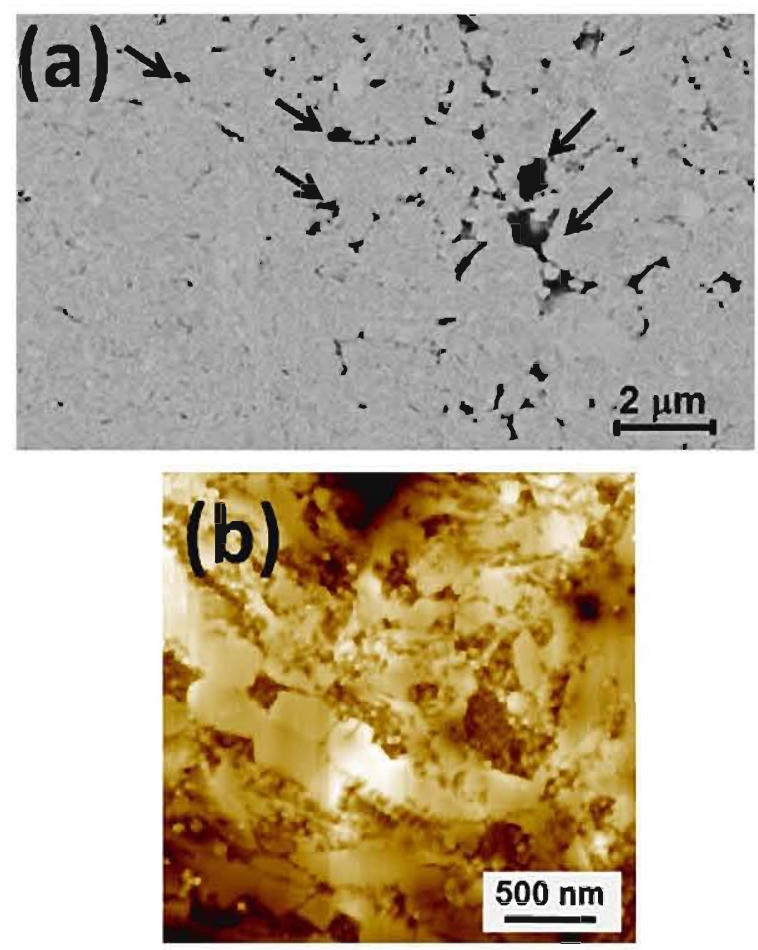

Fig. 5. Mictostructure of consolidated W-2Ti. (a) EBS-SEM image; the Ti pools arc inclicated by arrows. (b) AFM inage.

observed sub-micron Ti-rich regions correspond to TiC particles. These particles are homogenously distributed indicating that a good dispersion of submicron TiC particles may be developed in $W$ under the present conditions of milling. 

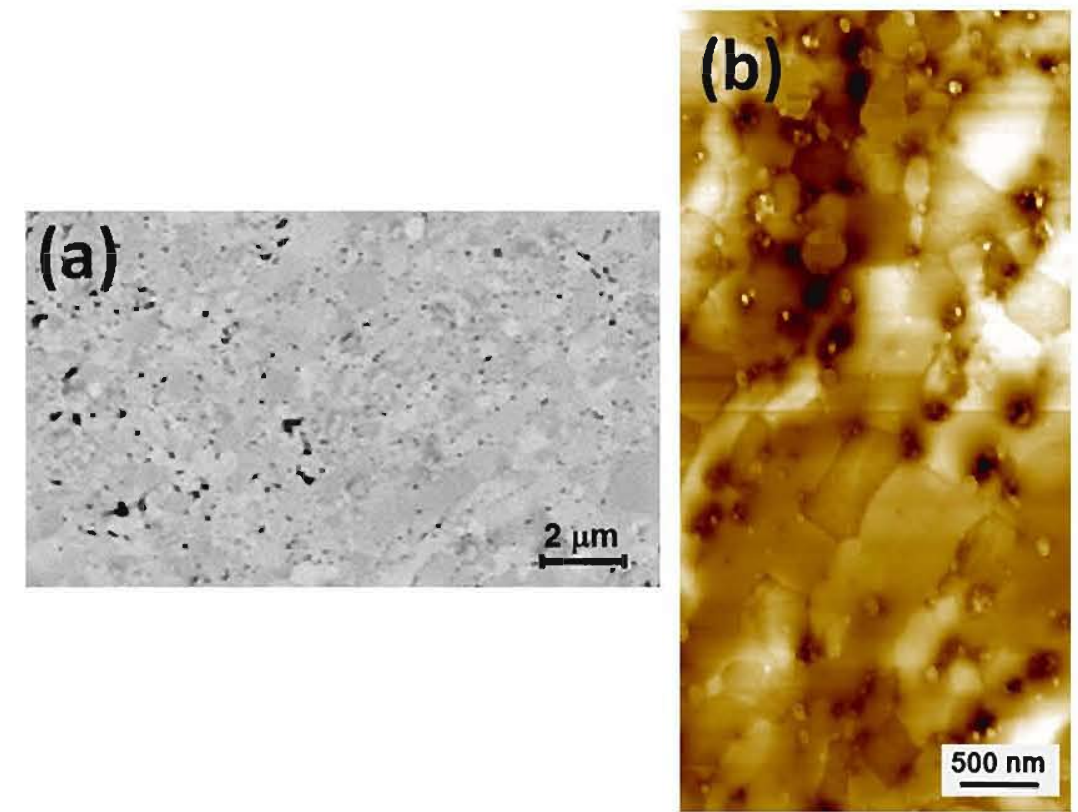

Fig. 6. Microstructure of consolidated W-1TiC. (a) EBS-SEM image. (b) AFM image.
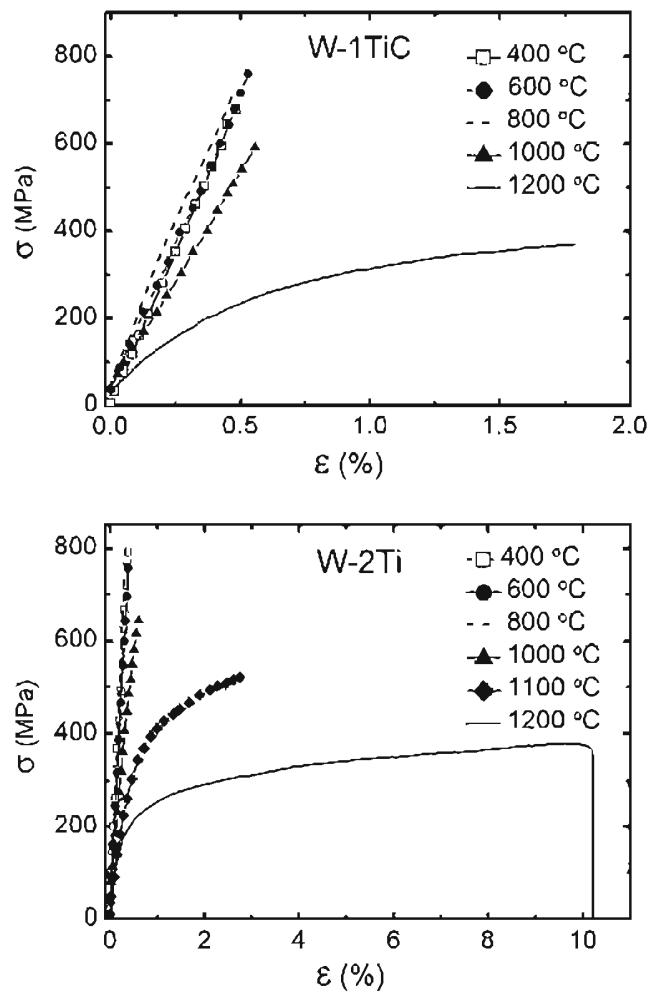

Fig. 7. Stress-strain curves of three point bending tests for W-1TiC and W-2Ti at different temperatures.

Table 2

Three point bending yield strength for $W-2 T i$ and $W-1 T i C$.

\begin{tabular}{lll}
\hline & $\begin{array}{l}1100^{\circ} \mathrm{C} \\
(\mathrm{MPa})\end{array}$ & $\begin{array}{l}1200^{\circ} \mathrm{C} \\
(\mathrm{MPa})\end{array}$ \\
\hline $\mathrm{W}-2 \mathrm{Ti}$ & $526 \pm 4$ & $381 \pm 4$ \\
$\mathrm{~W}-1 \mathrm{TiC}$ & - & $340 \pm 10$ \\
\hline
\end{tabular}

\subsection{Consolidated alloys}

The Vickers microhardness of consolidated alloys, along with the densities and $O$ contents are given in Table 1 . As expected, the relative density of the alloy $\mathrm{W}-2 \mathrm{Ti}$ alloy is significantly higher than the one measured for the W-1TiC alloy because Ti favors the densification of the material [20]. The $O$ contents measured in the consolidated alloys were considerably lower than corresponding contents in the as-milled powders. The Vickers microhardness for $W-2 T i$ is twice that for $W-1 \mathrm{TiC}$, i.e. 14.0 against $7.0 \mathrm{GPa}$. The value obtained for W-1TiC is somewhat lower than the one of 8.1 reported for $W$-5TiC [20], and that found for $W-0.57 i C$ (8.8$10.8 \mathrm{GPa}$, depending on the grain size) [21]. Figs. 5 and 6 show SEM and AFM images of the consolidated alloys. Both alloys exhibit an intermingled grain structure that consists of a population of submicron-sized grains and another one of coarser grains with sizes $\sim 1 \mu \mathrm{m}$ (see Figs. 5b and 6b). In the case of W-2Ti, the EDSSEM analyses reveal the presence of small Ti pools localized in the interstices between some $W$ prior particles. The formation of similar pools has also been reported in ODS $\mathrm{W}$-Ti and ODS $\mathrm{W}-\mathrm{V}$ alloys processed under similar conditions but mechanically alloyed for shorter period of time $[18,19]$. Since the milling time for the present alloys was up to three times longer than those for the ODS $W$ alloys and the formation of Ti pools is also produced, the present results confirm that this phenomenon is due to Ti segregation to the prior particle boundaries induced by the HIP process.

\subsection{Three-point bending tests}

Fig. 7 shows the temperature effect on the bending behavior of the alloys. The stress-strain curves for $\mathrm{W}-2 \mathrm{Ti}$ reveal plastic deformation at $T \geqslant 1000^{\circ} \mathrm{C}$ and completely brittle behavior at lower temperatures. The bending strength and the yield strength at $0.2 \%$ of plastic deformation are calculated using the equation:

$\sigma=\frac{3 P L}{2 t w^{2}}$

and the strain is determined from the expression:

$c=\frac{6 w \delta}{L^{2}} 100$ 
where $P$ is the breaking load, $L$ is the span (distance between the support points), $w$ is the specimen width, $t$ is the thickness of the sample and $\delta$ is the deflection. This alloy appears to exhibit better bending strengths at low temperature than corresponding strengths reported for the W-4Ti alloy, which did not show plastic deformation up to $1000^{\circ} \mathrm{C}$ [14]. The $\mathrm{W}-1 \mathrm{TiC}$ alloy exhibits plastic deformation at $1200^{\circ} \mathrm{C}$ and a completely brittle behavior at $T \leqslant 1000^{\circ} \mathrm{C}$. The yield strength values at $0.2 \%$ of plastic strain above $1100^{\circ} \mathrm{C}$ are shown in Table 2 . It should be noticed that the bending strength at $1100^{\circ} \mathrm{C}$ for other $\mathrm{W}$ alloys processed by the same route is noticeably lower, i.e. around $300 \mathrm{MPa}$ for pure $\mathrm{W}$ and around $350 \mathrm{MPa}$ for ODS $\mathrm{W}-2 \mathrm{Ti}-0.5 \mathrm{Y}_{2} \mathrm{O}_{3}$ and $\mathrm{W}-4 \mathrm{Ti}-0.5 \mathrm{Y}_{2} \mathrm{O}_{3}[18,22]$.

According to the three point bending tests, these $\mathrm{W}-2 \mathrm{Ti}$ and $\mathrm{W}-$ $1 \mathrm{TiC}$ alloys have the ductile-brittle transition above $1000^{\circ} \mathrm{C}$, which is higher than that of pure $W$. The powder metallurgy route is able to dissolve a part of the Ti particles in the $\mathrm{W}$ matrix for $\mathrm{W}-2 \mathrm{Ti}$ and, in case of $\mathrm{W}-1 \mathrm{TiC}$, a certain amount of TiC particles are well dispersed inside the $\mathrm{W}$ grains. However, the compositional and microstructural analyses indicated that $\mathrm{Ti}$ and $\mathrm{TiC}$ particles are found segregated at the grain boundaries. Furthermore, a non-negligible $\mathrm{O}$ concentration is also present in the alloys, which may also be segregated at the grain boundaries forming complex oxides. These phases segregated would develop a high concentration of internal stress in the grain boundaries promoting the grain boundary decohesion and brittleness of the alloys, as it occurs in Mo alloys [23]. In the case of $\mathrm{W}-1 \mathrm{TiC}$, the segregation of TiC particles at the boundaries might be avoided by substituting the mechanical alloying by some wetchemical process like that applied for processing Mo alloys [23].

\section{Conclusions}

W-2Ti and $\mathrm{W}-1 \mathrm{TiC}$ processed by mechanical alloying and HIP exhibit a grain structure containing a population of submicronsized grains and another of coarser grains with sizes $\sim 1 \mu \mathrm{m}$. The XRD measurements and the EDS analyses of the alloyed W-2Ti powders reveal the virtual dissolution of Ti into $\mathrm{W}$ under the present milling conditions. However, after HIP consolidation a fraction of $\mathrm{Ti}$ is found segregated in the interstices among prior powder particles. The SEM and EDS analyses show an apparent dispersion of TiC into $\mathrm{W}$ in the alloyed $\mathrm{W}-1 \mathrm{TiC}$ powder, but very small TiC particles appears decorating grain boundaries of the consolidated material.

The high microhardness value and the mechanical behavior at high temperature of the W-2Ti alloy may be attributed to solid solution hardening and grain boundary decohesion due to Ti segregation. In contrast, the much lower microhardness value in $\mathrm{W}$ $1 \mathrm{TiC}$, as well as the bending strain at $1200^{\circ} \mathrm{C}$, could be mainly caused by residual porosity excess since the densification grade attained was low, i.e. $95.3 \%$ against $98 \%$ for $\mathrm{W}-2 \mathrm{Ti}$.

\section{Acknowledgements}

This investigation was supported by the Spanish Ministry of Economy and Competitiveness (Projects ENE2012-39787-C06-05 and MAT2012-38541-C02-02), the Comunidad de Madrid through the programs ESTRUMAT-CM (S2009/MAT-1585), and TECHNOFUSION (S2009/ENE-1679), the CEI Campus Moncloa and the European Commission through the European Fusion Development Agreement. E. Tejado thanks CSIC and FSE for the JAE-Predoc grant.

\section{References}

[1] V. Philipps, J. Nucl. Mater. 415 (2011) S2-S9.

[2] M. Rieth et al., J. Nucl. Mater. 432 (2013) 482-500.

[3] M. Rieth et al., J. Nucl. Mater. 417 (2011) 463-467.

[4] H. Bolt, V. Barabash, W. Krauss, J. Linke, R. Neu, S. Suzuki, N. Yoshida, ASDEX Upgrade Team, J. Nucl. Mater. 66 (2004) 329-333.

[5] P. Norajitra, L.V. Boccaccini, E. Diegele, V. Filatov, A. Gervash, R. Giniyatulin, S. Gordeev, V. Heinzel, et al., J. Nucl. Mater. 329-333 (2004) 1594-1598.

[6] J.W. Davis, V.R. Barabash, A. Makhankov, L. Plöchl, K.T. Slattery, J. Nucl. Mater. $258-263$ (1998) 308-312.

[7] W.D. Klopp, J. Less-Common Metals 42 (1975) 261-278.

[8] M. Faleschini, H. Kreuzer, D. Kiener, R. Pippan, J. Nucl. Mater. 367-370 (2007) 800-805.

[9] Q. Wei, T. Jiao, K.T. Ramesh, E. Ma, L.J. Kecskes, L. Magness, R. Dowding, V.U. Kazykhanov, R.Z. Valiev, Acta Mater. 54 (2006) 77-87.

[10] Y. Nemoto, A. Hasegawa, M. Satou, K. Abe, J. Nucl. Mater. 283-287 (2000) $1144-1147$.

[11] A. Luo, D.L. Jacobson, KS. Shin, Int J. Refract Metal Hard Mater. 2 (1991) 107 114.

[12] E.Y. Ivanov, C. Suryanarayama, B.D. Bryskin, Mater. Sci. Eng. A251 (1998) 255 261.

[13] A. Muñoz, M.A. Monge, B. Savoini, M.E. Rabanal, G. Garcês, R. Pareja, J. Nucl Mater. 417 (2011) 508-511.

[14] M.V. Aguirre, A. Martín, J.Y. Pastor, J. LLorca, M.A. Monge, R. Pareja, Metall. Mater. Trans. A 40A (2009) 2283-2290.

[15] H. Li, S. Wurster, C. Motz, L. Romaner, C. Ambrosch-Draxl, R. Pippan, Acta Mater. 60 (2012) 748-758.

[16] J. Rodríguez-Carvajal, Physica B 192 (1993) 55

[17] D. Martínez-Blanco, P. Gorria, J.A. Blanco, M.J. Pêrez, J. Campo, J. Phys.: Condens. Matter 20 (2008) 335213. 10pp.

[18] T. Palacios, J.Y. Pastor, M.V. Aguirre, A. Martin, M.A. Monge, A. Muñoz, R. Pareja J. Nucl. Mater. 442 (2013) S277-S281.

[19] J. Martínez, B. Savoini, M.A. Monge, A. Muñoz, R. Pareja, Fusion Eng. Des. 86 (2011) 2534-2537.

[20] Y. Chen, Y.C. Wu, F.W. Yu, J.L. Chen, Int. J. Refract Metal Hard Mater. 26 (2008) 525-529.

[21] H. Kurishita, S. Kobayashi, K. Nakai, T. Ogawa, A. Hasegawa, K Abe, H. Arakawa S. Matsuo, T. Takida, K Takebe, M. Kawai, N. Yoshida, J. Nucl. Mater. 377 (2008) 34-40.

[22] M.V. Aguirre, A. Martín, J.Y. Pastor, J. LLorca, M.A. Monge, R. Pareja, J. Nucl. Mater. 404 (2010) 203209.

[23] G. Lui, G.J. Zhang, F. Jiang, X.D. Ding, Y.J. Sun, J. Sun, E. Ma, Nat. Mater. 12 (2013) 344-350. 